\title{
OBSCENIDADE REFLETIDA: NOÇÕES E RESSONÂNCIAS PORNOGRÁFICAS
}

\author{
Luciene Galvão-Viana $^{1}$ \\ Luciana Vieira ${ }^{2}$
}

\begin{abstract}
Resumo: O presente artigo tem por objetivo discutir articulações teóricas e proposições conceituais relativas à investigação pornográfica. Para tanto, utilizamos dados de uma busca textual no banco de teses e dissertações da Coordenação de Aperfeiçoamento de Pessoal de Nivel Superior (Capes), e na Scientific Electronic Library Online (Scielo), no periodo de julho a dezembro de 2012, e uma revisão dos estudos sobre a investigação pornográfica no Brasil, que tem se debruçado sobre a temática tomando como referência convenções de sexualidade e erotismo e o mercado do sexo. Argumentamos que é fundamental considerar uma perspectiva histórica ao tratar das produções pornográficas de modo a rejeitar interpretações invariavelmente homogêneas, unívocas e reducionistas. Tal argumento se baseia ainda na ideia de que a obscenidade, um dos elementos-chave nessas produções, implica jogos discursivos que são múltiplos, dispersos e ambíguos e que, apenas contingencialmente, atingem contornos definidos.
\end{abstract}

Palavras-chave: Pornografia. Obscenidade. Levantamento bibliográfico.

A pornografia, como a beleza, a qualidade e o humor, pertence a essa classe de coisas curiosas que acreditamos reconhecer todo o tempo sem nunca poder definí-las. (Bernard Arcand. El jaguar y el oso hormiguero: antropología de la pornografía).

$\mathrm{Na}$ língua portuguesa, a pornografia denota uma característica de produções que ferem o pudor, pois são obscenas e licenciosas. Além do mais, pode exprimir qualquer coisa realizada com o intuito de explorar o sexo atrativamente e de maneira chula e, corriqueiramente, ela pode ser vista como uma violação ao recato e à reserva, sendo sinônimo de indecência, de libertinagem e de imoralidade (HOUAISS, 2001). Nessas noções, os atos, as obras e as intenções são, indubitavelmente, sexuais e imorais.

No entanto, como têm demonstrado estudos dedicados à apreciação e à pesquisa de espaços, atos e produções referidos como pornográficos, tal adjetivação não é desprovida de disputas históricas e a destreza com que ela acontece mostra muito pouco sobre aquilo que é exibido em si, revelando frequentemente valores morais e posições políticas. Para dar início à pesquisa de referências bibliográficas acerca da pornografia, uma das etapas da realização da dissertação de mestrado ${ }^{3}$, nós realizamos uma busca textual no banco de teses e dissertações da Coordenação de Aperfeiçoamento de Pessoal de Nível Superior (Capes), e na Scientific Electronic Library Online (Scielo), no período de julho a dezembro de 2012. Utilizando o escritor "pornografia" e refinando a busca com o uso dos filtros "Idioma: português" e "Periódicos revisados por pares,"

\footnotetext{
1 Mestre em Psicologia pela Universidade Federal de Pernambuco. E-mail: lucienegalvaoviana@hotmail.com

${ }^{2}$ Professora do Programa de Pós-Graduação em Psicologia da Universidade Federal de Pernambuco. Email: E-mail: lufontesvieira@hotmail.com

${ }^{3}$ GALVÃO-VIANA. L. A folia dos cus prolapsados: pornografia bizarra e prazeres sexuais anais entre mulheres. 2014.
} 
encontramos 25 resultados publicados entre os anos 2003 e $2012^{4}$. Os títulos encontrados, organizados de acordo com o ano de publicação, foram os seguintes:

\section{Quadro 1: Levantamento bibliográfico utilizando o descritor "pornografia" no banco de teses e dissertações da Coordenação de Aperfeiçoamento de Pessoal de Nível Superior (Capes), e na Scientific Electronic Library Online (Scielo), no período de julho a dezembro de 2012.}

\begin{tabular}{|c|c|c|c|}
\hline $\begin{array}{l}\text { Base de } \\
\text { dados }\end{array}$ & Ano & Títulos & Autores \\
\hline Capes & 2003 & Relações de violência e erotismo & Maria Filomena Gregori \\
\hline Capes & 2003 & O efeito obsceno & Eliane Robert Moraes \\
\hline $\begin{array}{l}\text { Capes e } \\
\text { Scielo }\end{array}$ & 2003 & $\begin{array}{l}\text { Pedófilo, quem és? A pedofilia na mídia } \\
\text { impressa }\end{array}$ & Tatiana Savoia Landini \\
\hline $\begin{array}{l}\text { Capes e } \\
\text { Scielo }\end{array}$ & 2004 & $\begin{array}{l}\text { Atitudes de estudantes universitários diante do } \\
\text { consumo de materiais pornográficos } \\
\text { (Psicologia) }\end{array}$ & $\begin{array}{l}\text { Valeschka Martins Guerra } \\
\text { Fernando Cezar B. De Andrade } \\
\text { Mardonio Rique Dias }\end{array}$ \\
\hline $\begin{array}{l}\text { Capes e } \\
\text { Scielo }\end{array}$ & 2004 & $\begin{array}{l}\text { Observações sobre a libido colonizada: tentando } \\
\text { pensar ao largo do patriarcado }\end{array}$ & Hilan Bensusan \\
\hline Capes & 2006 & $\begin{array}{l}\text { Observações sobre a política dos } \\
\text { desejos: tentando pensar ao largo dos instintos } \\
\text { compulsórios }\end{array}$ & Hilan Bensusan \\
\hline $\begin{array}{l}\text { Capes e } \\
\text { Scielo }\end{array}$ & 2006 & $\begin{array}{l}\text { Violência sexual contra crianças na mídia } \\
\text { impressa: gênero e geração }\end{array}$ & Tatiana Savoia Landini \\
\hline Capes & 2007 & $\begin{array}{l}\text { Crítica social e ideias médicas nos excessos do } \\
\text { desejo: uma análise dos "romances para } \\
\text { homens" de finais do século XIX e início do } \\
\text { XX }\end{array}$ & Alessandra El Far \\
\hline $\begin{array}{l}\text { Capes e } \\
\text { Scielo }\end{array}$ & 2008 & $\begin{array}{l}\text { O Significado da compra: desejo, demanda e o } \\
\text { comércio do sexo }\end{array}$ & Elizabeth Bernstein \\
\hline Capes & 2008 & Giros em falso no debate da teoria & Fabio Akcelrud Durão \\
\hline Capes & 2008 & A Contribuição da crítica feminista à ciência & Lourdes Bandeira \\
\hline
\end{tabular}

\footnotetext{
${ }^{4}$ Utilizamos os filtros em decorrência do tempo destinado à realização do levantamento bibliográfico durante o curso de pós-graduação, bem como a nossa curiosidade quanto à especificidade da produção acadêmica sobre pornografia em língua portuguesa. O segundo filtro, observamos posteriormente, delimitou o acesso apenas às produções disponíveis em revistas indexadas. Desconsideramos as resenhas publicadas em tais revistas, para este levantamento inicial, pois elas faziam menção a livros que foram incorporados à pesquisa em momento posterior.
} 


\begin{tabular}{|c|c|c|c|}
\hline Scielo & 2009 & $\begin{array}{l}\text { Por um feminismo queer: Beatriz Preciado e a } \\
\text { pornografia como pré-textos }\end{array}$ & Salomé Coelho \\
\hline $\begin{array}{l}\text { Capes e } \\
\text { Scielo }\end{array}$ & 2010 & $\begin{array}{l}\text { Debates feministas sobre pornografia } \\
\text { heteronormativa: estéticas e ideologias da } \\
\text { sexualização (psicologia) }\end{array}$ & $\begin{array}{l}\text { Pedro Pinto } \\
\text { Maria da Conceição Nogueira } \\
\text { João Manuel de Oliveira }\end{array}$ \\
\hline Capes & 2011 & $\begin{array}{l}\text { Multidões queer: notas para uma política dos } \\
\text { anormais }\end{array}$ & Beatriz Preciado \\
\hline Capes & 2011 & $\begin{array}{l}\text { Ativismo artístico: engajamento político e } \\
\text { questões de gênero na obra de Barbara Kruger }\end{array}$ & $\begin{array}{l}\text { Lina Alves Arruda } \\
\text { Maria de Fátima Morethy Couto }\end{array}$ \\
\hline Capes & 2011 & $\begin{array}{l}\text { Gênero, epistemologia e performatividade: } \\
\text { estratégias pedagógicas de subversão }\end{array}$ & Anselmo Peres Alós \\
\hline $\begin{array}{l}\text { Capes e } \\
\text { Scielo }\end{array}$ & 2012 & $\begin{array}{l}\text { Race fucker: representações raciais na } \\
\text { pornografia }\end{array}$ & Osmundo Pinho \\
\hline $\begin{array}{l}\text { Capes e } \\
\text { Scielo }\end{array}$ & 2012 & $\begin{array}{l}\text { Altporn, corpos, categorias e cliques: notas } \\
\text { etnográficas sobre pornografia on-line }\end{array}$ & Carolina Parreiras \\
\hline Capes & 2012 & $\begin{array}{l}\text { Discursos em movimento: considerações sobre } \\
\text { a pedofilia e pornografia infantil na rede } \\
\text { (psicologia) }\end{array}$ & $\begin{array}{l}\text { Vivian Lemes Moreira } \\
\text { Lucília Maria Sousa Romão }\end{array}$ \\
\hline $\begin{array}{l}\text { Capes e } \\
\text { Scielo }\end{array}$ & 2012 & $\begin{array}{l}\text { Labirintos conceituais, científicos e } \\
\text { mercadológicos: pornografia com pessoas que } \\
\text { transitam entre os gêneros }\end{array}$ & Jorge Leite Júnior \\
\hline Capes & 2012 & Screening sex: revelando e dissimulando o sexo & Linda Williams \\
\hline $\begin{array}{l}\text { Capes e } \\
\text { Scielo }\end{array}$ & 2012 & Pornô & Don Kulick \\
\hline Capes & 2012 & $\begin{array}{l}\text { Entre vapores \& vídeos pornôs: dissidências } \\
\text { homo/eróticas na trama discursiva do } \\
\text { envelhecimento masculino }\end{array}$ & Fernando Altair Pocahy \\
\hline Capes & 2012 & $\begin{array}{l}\text { Os agentes sociais da rede de proteção e } \\
\text { atendimento no enfrentamento da exploração } \\
\text { sexual comercial (psicologia do } \\
\text { desenvolvimento) }\end{array}$ & $\begin{array}{l}\text { Maria de Fátima Pereira Alberto } \\
\text { Ana Cristina Serafim da Silva } \\
\text { Vanessa Cavalcante Gomes } \\
\text { Roberta Valesca Mota Santana } \\
\text { Àdria Melo Soares }\end{array}$ \\
\hline Capes & 2012 & $\begin{array}{l}\text { Perícia psicológica no abuso sexual de crianças } \\
\text { e adolescentes (psicologia) }\end{array}$ & $\begin{array}{l}\text { Luiziana Souto Schaefer } \\
\text { Silvana Rossetto } \\
\text { Christian Haag Kristensen }\end{array}$ \\
\hline
\end{tabular}


Considerando que o critério de busca utilizado, tanto pela base de dados da Capes, quanto da Scielo, é a quantidade de vezes que a palavra é citada nos textos. Acreditamos que ambas as fontes sejam uma ferramenta de pesquisa útil, pois oferecem um panorama dos títulos que apresentam perspectivas e abordagens variadas. No entanto, alguns dos títulos encontrados apenas citavam a pornografia, não tendo entre seus objetivos principais discuti-la. Em oito artigos das produções citadas, a palavra pornografia foi usada para reivindicar a qualidade de obras ficcionais que, por este motivo, não devem ser colocadas no mesmo patamar das pornográficas. Critica-se que as películas sexuais tenham um efeito de realidade e de pedagogia sexual sobre a sexualidade, quando deveriam alargar as possibilidades de compreensão e vivências eróticas, mas também se considera que elas são capazes de expor o desejo sexual mais genuíno, mesmo que, por vezes, de maneira degradante.

Dentre os 25 artigos, 5 foram publicados em revistas da área da Psicologia ou escritos por psicólogos. No primeiro deles, intitulado "Atitudes de estudantes universitários frente ao consumo de materiais pornográficos," Valeschka Guerra, Fernando de Andrade e Mardonio Dias argumentam que a expansão de produtos pornográficos é um efeito dos valores difundidos pela mídia sobre o comportamento dos indivíduos, cujo objetivo era validar um instrumento para avaliar as atitudes diante do consumo pornográfico. Nesta pesquisa, 336 estudantes universitários foram entrevistados e suas respostas, divididas em 33 itens correspondentes a duas dimensões: efeitos positivos e nocivos da pornografia (GUERRA; ANDRADE; DIAS, 2004).

Os psicólogos concluíram que o grupo de consumidores é formado por homens que utilizam a pornografia para obter prazer e discordam da ideia de que o pornô seja sinônimo de banalização do sexo ou o seu consumo frequente, um vício. No grupo de não consumidores, majoritariamente formado por mulheres, a pornografia é considerada prejudicial ao desenvolvimento da sexualidade, por provocar isolamento e alienação, sendo, por este motivo, vista com pouca frequência. Os pesquisadores afirmam que o instrumento elaborado para o estudo foi validado, porém, posteriormente, seria necessário sofisticar a análise e desenvolver outros instrumentos para problematizar a diferença de gênero que os resultados evidenciam, bem como contribuir para remediar a lacuna de conhecimentos sobre a sexualidade dos brasileiros (GUERRA; ANDRADE; DIAS, 2004).

Em outro artigo "Discursos em movimento: considerações sobre a pedofilia e pornografia infantil na rede", Vivian Moreira e Lucília Romão informam que o termo pornografia infantil é usado para definir representações, reais ou simuladas, de crianças e adolescentes em atividades sexuais ou exibição dos órgãos sexuais de maneira explícita com finalidade sexual (MOREIRA; ROMÃO, 2012, p.466). O terceiro artigo que apresenta dados sobre a percepção dos Agentes Sociais que atuam no enfrentamento da exploração sexual trata da pornografia como um dos abusos sexuais sensoriais extra ou intrafamiliar, assim como do exibicionismo e da linguagem sexualizada. O termo pornografia infantil também se refere à elaboração de materiais, bem como a divulgações e exibições de crianças envolvidas em atividades sexuais (ALBERTO et al., 2012). 
A pornografia também é mencionada na literatura psicológica relacionada à investigação de abusos sexuais no artigo "Perícia psicológica no abuso sexual de crianças e adolescentes", que objetiva revisar o papel da perícia psicológica no atendimento ao abuso sexual de crianças e adolescentes (SCHAEFER; ROSSETTO; KRISTENSEN, 2012). Os últimos três títulos da área psi encontrados no levantamento discutem pedofilia, pornografia infantil, abuso sexual de crianças e adolescentes e a perícia psicológica diante desses casos. Tais temas são bastante controversos e têm sido amplamente discutidos, considerando os marcos internacionais dos direitos das crianças e dos adolescentes e as diretrizes para atuação profissional dos psicólogos. No entanto, uma vez que, neste trabalho, estamos tratando de representações obscenas produzidas e encenadas por pessoas que têm idade superior a 18 anos, não nos ateremos a discutilos. ${ }^{5}$

Nos demais artigos mencionados, mesmo que os objetivos não estejam direcionados à discussão sobre a noção de pornografia, ela é produzida como sinônimo de práticas sexuais, como fenômeno midiático ou como um imaginário normatizado e, em todas as situações citadas, potencialmente nociva a uma sexualidade ideal. Tal posição discursiva foi observada por Feona Attwood (2011) em um levantamento sobre pesquisa pornográfica e o debate público anglo-americano. Para a autora, o debate público continua a evidenciar discursos que dão ênfase apenas aos perigos e efeitos da pornografia mesmo com a diversidade de formas com que o tema tem sido tratado nas universidades.

Uma das perspectivas possíveis de abordagem pornográfica que se contrapõe à nocividade pornográfica é a centralidade do jogo de ocultamento e de explicitação da palavra obscena, um dos elementos de uma tradição pornográfica que se inicia no Renascimento, na Europa do século XVI, e que coloca em circulação imagens e palavras que ferem o pudor ao fazer do sexo o personagem principal (HUNT, 1999). Conforme Eliane Moraes (2003), a literatura renascentista, mais precisamente o escritor Pietro de Aretino, deu origem a elementos cruciais para a formação da cultura pornográfica ocidental, na medida em que difundiu e popularizou expressões que antes ficavam restritas a um pequeno grupo de doutos e escritores licenciosos.

Aretino nasceu em Arezzo, Itália, em 1492, e foi notabilizado já em 1512 por sua produção satírica, que tratava dos sucessos e desventuras de senhores, cardeais e papas do Vaticano. Seu tom ácido, soberbo e irreverente lhe proporcionou amizades, através das quais ele podia manter hábitos dignos da nobreza italiana, mas também provocou inimizades e, por causa destas, o poeta italiano teve que fugir, diversas vezes, dos lugares onde residia. Radicado em Veneza em 1527, ele se tornou o centro da vida mundana e intelectual da cidade. Além dos sonetos, escrevia epístolas, sendo considerado um dos precursores do jornalismo moderno, defendendo que os escritores pudessem viver do seu trabalho e não da generosidade dos mecenas.

Aretino faleceu em 1556, em Veneza, cidade a qual ele se referia como "pátria universal, liberdade comum e albergue de gente dispersa" (PAES, 2011). Sonetos luxuriosos (1527) está entre as suas mais importantes obras e foi escrita para

\footnotetext{
${ }^{5}$ Para aprofundar a discussão, consultar: Da Silva (2013), Landini (2005) e Méllo (2006).
} 
acompanhar gravuras eróticas do pintor Giulio Romano, quando a maior parte da população europeia não era alfabetizada. De fato, a democratização de materiais obscenos, experimentada ainda hoje, não teria se consolidado sem a intenção realista e deliberadamente transgressora dos costumes sociais do escritor (LEITE JÚNIOR, 2006; MORAES, 2003).

Em meados do século XVII, a transgressão dos costumes provocada pela literatura obscena contou, significativamente, com o desenvolvimento de novas tecnologias de impressão, que possibilitaram produzir e distribuir em larga escala, barateando os custos de comercialização, como também dispôs da produção de materiais de ajuda sexual, considerados os primeiros "consolos-de-viúva", e preservativos, em Londres e na Itália, respectivamente. Juntamente com a cultura do material impresso, a prosa pornográfica caracterizou-se nesse período por ter como objetivo a exposição de materiais, cada vez mais realistas sobre o ato sexual em contraponto às representações sexuais metafóricas sob domínio da Igreja e em consonância à ciência da época, que já se debruçava sob a catalogação dos prazeres amorais que eram justificados tão somente pelas leis físicas e naturais (HUNT, 1999).

O século XVIII, por sua vez, será marcado pelo pensamento iluminista, trazendo para o campo erótico a ideia de que o desejo sexual é uma instância natural, enquanto que a sua proibição e punição é que seriam artificiais e indevidas, pois o sexo e a paixão tinham efeitos benéficos e proporcionavam a felicidade para a humanidade. Os órgãos sexuais e a cópula eram ainda símbolos de grande força e veneração. Nos romances eróticos desse período de veneração sexual, a prostituta e o homossexual eram personagens limites. As prostitutas, por não gozarem das alegrias domésticas e maternas, e o homossexual, por praticar sodomia passiva com outros homens (TRIMBACH, 1999).

Além de Aretino, figura ainda mais basilar, polêmica e indissociável da produção obscena até o século XVIII é Donatien-Alphonse-François ou Marquês de Sade, pois, segundo a historiadora Lynn Hunt (1999), ele seria incomparável por explorar, ao extremo, o pornográfico de aniquilação do corpo em nome do desejo. A obra de Sade foi publicada clandestinamente no século XIX e proibida em alguns países ainda durante o século XX. Adepto da ideia de que a liberdade humana só se realiza plenamente no mal, Sade passou metade de sua vida preso, e parte da vida em cárcere, no sanatório de Charenton, onde faleceu em 1814.

No entanto, Sade notabilizou-se principalmente por embarcar em uma forma de criação artística que recusa a realidade e opera uma espécie de ruptura com o mundo. A ruptura era condição para a criação, uma vez que "toda felicidade do homem está na imaginação" (MORAES, 2011). A diversidade dos personagens e das estranhas práticas sexuais, por ele criadas, permite considerar Les 120 journées de Sodome (1785) como um original Catálogo de Perversões, que só mais tarde serão deslocadas do campo do erotismo e da reflexão intelectual e, superficialmente, associadas tão somente a uma problemática moral e mercadológica (MORAES, 2003).

Para Foucault (2001), por outro lado, Sade formulou um erotismo regulamentar, anatômico, hierarquizado e meticulosamente distribuído em temporalidades calculadas, espaços esquadrinhados, vigilâncias e obediências próprias à sociedade disciplinar do 
século XVIII. Ao comentar sobre filmes da década de 1970, que recriavam um erotismo baseado na experiência nazista, Foucault afirma que é necessário inventar com o corpo - volátil e difuso em seus elementos, superfícies, volumes e densidades - um erotismo não disciplinar que em muito difere do erotismo criado por Sade, um sargento do sexo e contador de bundas e seus equivalentes.

Como enfatiza Sébastien Charles (2007), Foucault questiona Sade enquanto um escritor "apaixonado" que tem no Marquês o "coração" de suas reflexões sobre o sexo. Assim, o filósofo francês interroga o estatuto da obra sadiana mais do que o seu conteúdo, buscando aproximar-se discursivamente, principalmente no que se refere aos usos linguísticos "[...] fora de si mesmas pelo inumerável, o indizível, o estremecimento, o estupor, o êxtase, o mutismo, a pura violência, o gesto sem palavra e que são calculadas, com a maior economia e maior precisão [...]. Essas linguagens [...] são linguagens curiosamente duplas" (FOUCAULT, 2001, p.53).

Sendo assim, Foucault critica o Marquês enquanto um pensador da sexualidade, que utiliza uma linguagem que é residual até o século XIX e está indissociavelmente colocada entre o sagrado e o profano, o infinito e o finito, o sobrenatural e o natural e é concebida sob a forma da transgressão, ao mesmo tempo essencial e plural. Essencial, pois só a superamos ilusoriamente, e plural, considerando que a limitação linguística tenta integrar a sexualidade à naturalidade, tornando a espécie humana similar a outras espécies e fazendo com que a transgressão sexual seja um paliativo buscado incessantemente e de múltiplas formas, mas que está, a partir de Sade, integrada à linguagem (CHARLES, 2007).

Considerando a investigação pornográfica, Pietro Aretino e Marquês de Sade foram dois acontecimentos anteriores ao surgimento da pornografia moderna e pode-se afirmar que, até o século XIX, a representação explícita de órgãos e práticas sexuais tinha quase sempre a finalidade de crítica social e política para além da finalidade de eliciar sensações (HUNT, 1999). Por outro lado, a querela sobre a obscenidade, no período anterior ao século XIX, contribuiu também para a consolidação linguística da pornografia.

A palavra Pornografia advém da língua grega (pornographos) e significa escritos sobre prostitutas. O termo foi inicialmente utilizado para falar dos hábitos das prostitutas e de seus clientes (MORAES, 1985; MORAES, 2003). Mas, em 1769, o francês Restif de La Brettone, no tratado Le pornographe, utilizou o termo pornógrafo para se referir "aquele que escreve sobre prostitutas" e, apenas em 1840, pornographique, pornographe e pornographie farão menção a escritos e imagens obscenos.

Em 1806, Etienne-Gabriel Peignot publica na França o Dictionnaire critique, littéraire e bibliographique des principaux livres condamnés au feu, suprimés ou sensurés que ordenava livros que deveriam sair de circulação por justificativas religiosas, morais e políticas. No dicionário francês estavam listadas obras de cunho literário que agrediam os costumes, emitiam opiniões bizarras, perigosas, imorais e que suscitavam a necessidade de defender a sociedade. A obra Émile, de Jean-Jacques Rousseau, era um desses livros (HUNT, 1999). Le sopha, de Crébillon Fils (1742), Les bijoux indiscrets, de Diderot (1748) e o hoje famoso romance inglês, Fanny Hill, de John Cleland (1749), obtiveram repercussão semelhante (MORAES, 2003). 
Entre o fim do século XVIII e as primeiras décadas do século XIX, a criação das coleções particulares que foram denominadas de museus secretos e reuniam objetos classificados como pornográficos e o volume crescente de escritos sobre prostituição são duas ocorrências que terão como efeito a invenção da pornografia moderna (KENDRIK apud HUNT, 1999). Uma das cenas mais alegóricas do surgimento dos museus secretos aconteceu na Itália. Após a descoberta de objetos e imagens nas ruínas de Pompeia - representando possivelmente os hábitos sexuais da corte e dos mercadores do Império Romano -, o Museu Nacional de Arqueologia de Nápoles passa a tutelar tais objetos, restringindo a visitação de mulheres, crianças e operários às obras. A coleção das ruínas de Pompeia inicialmente é chamada de gabinete de objetos obscenos, depois de gabinetes de objetos reservados e, em 1860, Alexandre Dumas, então diretor do Museu, a denomina Coleção Pornográfica (FREIRE, 2000; HUNT, 1999; GRANT MULAS apud LEITE JÚNIOR, 2006).

No mesmo século, a fotografia e o cinema revolucionaram as artes em geral e a produção obscena em particular, modificando o panorama do protagonismo da literatura na história do pornô ocidental. A fotografia e seus desdobramentos foram privilegiados pelas técnicas de obtenção da imagem até a captação do movimento, característica cinematográfica. Assim, o cinema do século XIX se distinguiu de outras artes e afirmou sua linguagem na tentativa de captar a vida, tal como ela acontece. Dito de outra forma, a sétima arte tinha a tarefa de fascinar seus espectadores, exibindo simplesmente movimentos: dos objetos, dos automóveis, do corpo humano, de uma dança, de um beijo, etc (ABREU, 1996).

No século seguinte, entretanto, uma vez que a linguagem cinematográfica já havia se consolidado, as narrativas ficcionais e os discursos científicos adentram a grande tela, através das histórias cada vez mais complexas e diversificadas, incluindo a temática dos atos sexuais. Já nas primeiras décadas do século XX, a série francesa Positions mostrava os movimentos dos corpos nus de um casal heterossexual acompanhados pelos comentários de um sexólogo. A câmera enquadrada em plano médio não permitia ver os genitais e o ato sexual era subentendido pela movimentação corporal. Nesse período, também surgem os Stag Movies, filmes curtos, em preto e branco, que proporcionam um show genital marcado por mudanças bruscas, tanto temporalmente, quanto nos usos da iluminação, dos cortes e do enquadramento (ABREU, 1996).

Com relação à pintura, mesmo que haja, do Renascimento ao século XX, uma quantidade incontável de obras que reproduzem práticas sexuais, apenas as pinturas dos grandes mestres são comumente reconhecidas e, ainda assim, classificadas como arte erótica, e não como pornográficas (LEITE JÚNIOR, 2006). Estão entre eles alguns quadros de Agnolo Bronzino, Caravaggio, Diego Velázquez, Francisco de Goya e Eugène Delacroix. Nesse panorama, o incremento da produção pictórica e literária e o crescimento vertiginoso de um público de consumidores e leitores fazem surgir na Europa Ocidental e, posteriormente, nas Américas e nos Estados Unidos, uma classe independente de produções que fazem uso da obscenidade como um negócio e constituem um mercado específico ${ }^{6}$ (LEITE JÚNIOR, 2012; LEITE JÚNIOR, 2006).

\footnotetext{
${ }^{6}$ Não fazemos distinção nos usos das palavras pornografia e erotismo ou nos referimos às obras mencionadas e analisadas neste trabalho como pornográficas ou eróticas. Como discutem detidamente Sontag (1987), Arcand (1993), Hunt (1999), Moraes (2003) e Leite Júnior (2006), essa divisão se contrapõe à investigação histórica da pornografia moderna e se baseia em critérios políticos, morais e religiosos, que são depreciativos e discriminatórios.
} 
Se levamos em conta que as características da produção pornográfica até o século XIX não desapareceram por completo, mas se sobrepõem a características atuais, podese considerar os quadros Wrestling e Travesti, expostos no Museu do Poder, em São Petersburgo, como uma extensão do obsceno como crítica.

Recentemente, os quadros foram considerados extremistas pela polícia russa e a diretora do museu foi presa após tentar reabri-lo. Os quadros geraram polêmica por apresentar o presidente americano Barack Obama e o presidente russo Vladimir Putin nus e com pênis que se assemelham a mísseis balísticos, e o presidente Putin, penteando os cabelos do primeiro-ministro Dmitri Medvedev, ambos vestidos com lingeries. A prisão da diretora do museu foi justificada por uma lei que proíbe a propaganda intelectual, e outra que proíbe insultos a figuras do Estado. ${ }^{7}$ Deste modo, tal situação reafirma ainda que aquilo que deve estar fora de cena não causa incômodo em si, mas sim pelos efeitos daquilo que coloca em cena.

Como vimos, a palavra pornografia e suas variações eram utilizadas nos escritos sobre as prostitutas, nos dicionários oficiais, na literatura e em museus arqueológicos para a classificação de obras de arte. Com o desenvolvimento de tecnologias visuais e mercadológicas, o sentido do termo diversifica-se e se propaga.

\begin{abstract}
Não apenas a ciência vai criar categorias e conceitos para discursar e debater sobre os sexos, gêneros, desejos e práticas sexuais, mas também a nascente cultura de massas. Desta forma, o termo pornografia não se desenvolve como uma categoria científica - portadora de um rigor conceitual e de uma definição clara -, mas se consolida como uma ideia imprecisa, difundida no senso comum e alimentada pela indústria do entretenimento (LEITE JÚNIOR, 2012, p. 103).
\end{abstract}

Tal imprecisão conceitual instaurada com a diversificação da produção e do consumo impulsiona o vigor e a inventividade do mercado pornô, pois a fluidez e a incerteza classificatórias estimulam a criação de categorias e subcategorias infindáveis (LEITE JÚNIOR, 2012). De maneira análoga, os usos obscenos retomados nesse percurso histórico e a dispersão categórica que os caracterizam, principalmente quando do surgimento das tecnologias visuais e de mercado, também têm se diversificado as produções teóricas sobre a pornografia.

No levantamento inicial nas bases de dados Capes e Scielo, observamos que em parte dos artigos, mesmo que os objetivos não estejam direcionados à discussão sobre a noção de pornografia, ela é produzida como sinônimo de práticas sexuais, como fenômeno midiático, como um imaginário normatizado e como algo potencialmente nocivo a uma sexualidade ideal. Tal posição discursiva foi constatada também por Feona Attwood (2011) em um levantamento sobre pesquisa pornográfica e o debate público anglo-americano. Ela observa que apesar da diversidade de formas com que o tema tem sido tratado nas universidades, há a preponderância da ênfase aos perigos e aos efeitos da pornografia, com base em argumentos behavioristas.

\footnotetext{
7 Mais informações sobre o ocorrido podem ser obtidas nas reportagens abaixo: http://operamundi.uol.com.br/conteudo/noticias/30990/diretora + de + museu + que + expos + quadro + de + putin + em+lingerie + e+detida.shtml http://operamundi.uol.com.br/conteudo/noticias/30907/artista+russo+procura+asilo+depois +de+pintar+pu tin + de+lingerie.shtml.
} 
Argumentos behavioristas, para a autora, equivalem a compreender a mídia como forma de estímulo, mensagem ou conteúdo que causa resposta ou produz efeitos específicos naqueles que consomem materiais pornográficos, ignorando abordagens sobre representação e consumo midiático, teorias construcionistas sobre sexo e sexualidade ou quaisquer formas de conhecimentos culturalmente forjados. Consequentemente, a pornografia significaria algo abstrato e descontextualizado e, implicitamente, uma plataforma de exibição do sexo mercantilizado, casual ou estranho, moralmente errado e socialmente problemático.

Alinha-se à crítica behaviorista, uma abordagem feminista radical que considera que o pornô é uma forma de violência institucionalizada contra as mulheres e que a liberdade sexual é uma mera extensão dos privilégios masculinos (ATTWOOD, 2011; GREGORI, 2010). As feministas radicais são referidas como uma parcela da comunidade feminista lésbica que compunha os grupos antipornografia, no final da década de 1970, que repudiavam o sexo com homens a partir de uma leitura determinista das relações de poder entre homens e mulheres.

Catherine Mackinnon e os grupos Women Against Violence in Pornography and Media, Women Against Pornography foram expoentes da ideia de que as relações sexuais são estruturadas pela subordinação e, portanto, cabe invariavelmente aos homens os atos de dominação e, às mulheres, a submissão. Consequentemente, para essa posição antissexo, a sexualidade é sobreposta ao gênero. Além da pornografia, as feministas radicais militavam contra o sadomasoquismo, a prostituição, a pedofilia e a promiscuidade (GREGORI, 2003).

Gayle Rubin, no texto Thinking sex (1975), elaborou uma resposta teórica para o feminismo radical da década de 1970, detendo-se principalmente sobre o comportamento sexual não convencional e a prática sexual. A autora utiliza o termo diferença sexual para tratar das práticas e da variedade sexual e defende que a sexualidade tem sua política interna, desigualdades, conflitos de interesse e manobras políticas. Deste modo, para ela, o ato sexual é sempre político e há principalmente cinco formações ideológicas que o feminismo precisa dar-se conta para investigá-lo criticamente: a ideia do sexo como força natural e essencial, eternamente imutável e ahistórico; a noção de que a prática sexual é perigosa, destrutiva ou pecaminosa se desfrutada em demasia e além do ideal procriativo; o sistema hierárquico das sociedades ocidentais que faz com se valore tais atos e, consequentemente, as pessoas que os fazem, e, por fim, o fato de o sexo estar localizado entre a ordem e o caos sexual. Rubin (2003, p.70) argumenta também que

\footnotetext{
A maioria das pessoas tem dificuldade em compreender que aquilo que fazem sexualmente será repulsivo para alguém, e que alguma coisa que as repele sexualmente é o maior tesouro prazeroso para alguém, em algum lugar. Uma pessoa não precisa gostar ou fazer um ato sexual particular para que este ato seja reconhecido pelo desejo de outros, e que esta diferença não indica a falta de bom gosto, saúde mental, ou inteligência em qualquer uma das partes. A maioria das pessoas se equivoca ao posicionarem suas preferências sexuais como um sistema universal que vai ou deveria funcionar para todos.
} 
Filomena Gregori (2003) afirma que houve outras reações feministas à perspectiva radical na década de 1980. Entre elas, a realização de uma conferência que reuniu feministas heterossexuais e lésbicas e deu origem ao livro Danger and pleasure, publicado por Carol Vance, em 1984. Neste livro, elas recusam a associação da sexualidade a modelos que têm as relações de dominação como parâmetro e ampliam as discussões para a dualidade prazer x perigo. Prazer, pela possibilidade de transgredir os limites do sexo reprodutivo, e perigo, pois é preciso considerar aspectos relativos à violência que pode estar envolvida no exercício da sexualidade.

Assim, até a década de 1990, as preocupações com os efeitos do estímulo pornô e uma abordagem feminista radical serão predominantes nas produções acadêmicas, com exceção das obras The sadeian woman (CARTER, 1979), The secret museum: pornography in modern culture (KENDRICK, 1996), Hard core: power, pleasure and the frenzy of the visible (WILLIAMS, 1989), Sex exposed (SEGAL; MCINTOSH, 1992) e Dirty looks (GIBSON; GIBSON, 1993). Estes livros anteciparam a crítica sobre a nocividade da pornografia e iniciaram uma mudança de paradigma, influenciada pela crítica feminista radical e por ativistas e trabalhadores do sexo, a qual possibilitou incluir nas teorizações: contingências históricas, análises de consumo coletivo, ênfase aos modos de vida gay, à "queerização" do sexo e das normas de gênero e o questionamento da ideia de que as mulheres não são atraídas por representações sexualmente explícitas (ATTWOOD, 2011).

Por outro lado, proposições conceituais sobre pornografia e pesquisas sobre o mercado sexual têm adotado uma perspectiva distinta da que é delineada por Feona Attwood. A primeira proposição conceitual é dada por Eliane Moraes e Sandra Lapeiz (1985), em um dos primeiros textos acadêmicos dedicados à pornografia no Brasil. As autoras proferem que a característica principal do discurso pornográfico é a sexualidade e sua dispersão e ambígua discursividade: "a pornografia está nos livros e revistas eróticos, nas pornochanchadas, nos palavrões, nos grafitos, nos banheiros, nas ruínas de Pompeia, nos "gracejos" de rua, nos outdoors das avenidas, nas cartas de baralho, e na cabeça das pessoas" (MORAES; LAPEIZ, 1985, p.10).

O obsceno, por sua vez, pode ser entendido como aquilo que está fora de cena ou que se esconde na vida cotidiana. Segundo Havelock Ellis (apud ABREU, 1996), médico inglês e um dos pioneiros da sexologia no século XIX, o termo é uma variação da palavra latina scena. A pornografia se distingue por acionar o mecanismo particular da fantasia, característica que se contrapõe à homogeneização das ideações sexuais. Entretanto, o constrangimento da possibilidade de fantasiar e agir criativamente diante do sexo é justamente o mote crítico de discursos libertários que, já na década de 1980, pretendiam elaborar alternativas que privilegiassem "os órgãos em detrimento dos corpos e os corpos em detrimento dos seres" (MORAES; LAPEIZ, 1985, p. 139).

O coletivo Gang pode ser considerado um desses discursos, pois atuou no Rio de Janeiro entre os anos 1980 e 1984 e criticava a repressão e a normalização dos corpos intensificadas durante a ditadura militar brasileira. Ele trazia em suas performances o intuito de subverter a libido, a sensualidade, as relações afetivas, e de desconstruir palavras e termos habituais, como "tortura", "poder", "censura", "miséria", "fome", etc (NOGUEIRA, 2013). 
A elaboração dos atos enfocava a crítica à ortodoxia literária e pretendia propor a criação de novos modos de vida e comportamentos em oposição à homogeneidade e constância que são facilmente associadas ao pornô. ${ }^{8} \mathrm{O}$ Coletivo e suas intervenções performativas e poéticas foram os responsáveis pela criação do Movimento de Arte Pornô (MAP), que pretendia "compreender a lógica da pornografia, trazê-la para um universo de subversão e fazer dela uma ferramenta de combate político." O pornô era referido, nos atos do Coletivo, de maneira antagônica à arte, à política e à subversão, tradicionalmente problemático.

No entanto, há poucas referências sobre aquilo que pode ser considerado tradicional em termos de pornografia. A produção e a transmissão do obsceno, do século XVI ao século XIX, por exemplo, deram-se precisamente nos âmbitos artísticos e políticos. Não convencional, neste sentido, seria a separação entre a lógica pornô e a subversão ou entre obras pornográficas e obras artísticas.

Outra formulação conceitual é dada pela escritora Susan Sontag (1987). Ela propõe pensarmos três tipos de pornografia: 1) como um item da história social, 2) como um fenômeno psicológico (indicativo de deficiência ou deformidade sexual daqueles envolvidos na produção e no consumo) e 3) como uma modalidade no interior das artes. Embora tal divisão seja conflituosa - pois a patologização da produção e do consumo pornográficos e a elaboração de poesias, poemas e contos obscenos fazem parte do mesmo percurso histórico que se pode atribuir à pornografia moderna ocidental -, Sontag (1987) se destaca por afirmar a existência de uma experiência singular da pornografia no campo literário, se comparada a outros temas. Em uma de suas frases mais contundentes, a autora afirma que a pornografia, quando autêntica literatura, busca causar excitação sexual do mesmo modo que os livros que falam da experiência religiosa objetivam converter.

Sontag (1987) demarca a especificidade pornô no campo da literatura e aponta que as sensações físicas provocadas nos leitores são indissociáveis das experiências humanas, como personalidade e como corpo. Todavia, esta perspectiva permanece atrelada à separação metafísica que destina concepções e sensibilidades distintas ao corpo e à mente. Assim, não por acaso, uma experiência pornô pode se tornar similar a uma experiência religiosa.

Diferenciando-se radicalmente das ideias defendidas por Susan Sontag, o pesquisador John Court (1992) propõe uma resposta religiosa para conter o crescimento e a proliferação do consumo pornográfico entre cristãos. Ele afirma que o pornográfico não é condenável, por apresentar o sexo explicitamente ou por seu conteúdo sexual, mas pela maneira como são tratados os problemas sexuais, pela desumanização do sexo e pela coisificação dos seres humanos promovidas nessas obras. Desta forma, a pornografia não seria nociva de maneira autoevidente, mas, paradoxalmente, é necessário confrontá-la e substituir as atitudes sexuais - que são contra a vida, a família,

\footnotetext{
8 No blog Escritos com.corpo: Arte e Imaginação Política mantido por Fernanda Nogueira (http://fernandanogueira-escritos.blogspot.com.br/), há mais informações sobre o Coletivo Gang e a Plataforma FUNKCARIOCAQUEER destinada a traduções coletivas de textos do Movimento Queer para o português. A plataforma foi inaugurada em 2003 e enfatiza a urgência de não cumprir uma "quota disciplinar" para discussão acadêmica, mas democratizar o acesso às reflexões queer, atualizando expressões de acordo com o contexto brasileiro.
} 
o ser humano, a mulher, as crianças, o sexo, a sociedade, o meio ambiente, a comunidade, a cultura, a consciência e, finalmente, contra Deus - por reações carinhosas e atenciosas que tenham o poder de eliminar o desejo pornográfico individual e coletivamente.

Com tal argumentação, a pornografia explicitamente é tida como um problema inaceitável pela maneira como apresenta o sexo. A prosperidade pornô é aceita apenas quando envolve o ensino apropriado a respeito da sexualidade para noivos, casados e/ou adolescentes que devem entender o coito como uma dádiva sagrada destinada ao prazer, à intimidade e à intensa satisfação em uma relação amorosa e duradoura, que se opõe à decadência espiritual e moral, que é fazer do ato sexual um espetáculo público (COURT, 1992). Essa perspectiva considera a pornografia como sinônimo da atividade sexual e faz coincidir também certa noção de sexualidade e a necessidade de uma austeridade das condutas sexuais em detrimento do afeto. A sexualidade aqui é tida como um conjunto de regras morais que devem ser seguidas para a manutenção da ordenação social e familiar que, por sua vez, se baseia no cultivo de relações afetuosas, humanizadoras e espiritualizadas.

Tanto se adotarmos a perspectiva defendida por John Court (1992), quanto se defendermos a possibilidade de vivenciar o pornô com naturalidade, como qualquer outra experiência humana, permanece intocado o questionamento sobre o que faz com que a libido e o ato sexual tornem-se elementos fundamentais para a elaboração de formas de se relacionar que são individualizantes, impositivas e baseadas em ideais sexuais normativos. Em outras palavras, o enaltecimento da intimidade amorosa e de certa humanidade sexual parece funcionar como forma de atenuar o ato sexual licencioso, quando, de fato, apenas se refere à exigência de um uso saudável e adequado dos prazeres sexuais.

A pornografia com mulheres gordas, por exemplo, expõe que não é possível homogeneizar a crítica acerca da pornografia no que se refere aos prazeres e à atividade sexual. Neste segmento, o sexo não é visto como um ato entre duas pessoas com duração determinada e que acontece principalmente através da estimulação de zonas erógenas, com a finalidade de alcançar o orgasmo. O pornográfico aqui não se refere à exibição de um pênis, uma vagina ou um ânus, mas sim à introdução de comida na boca de uma mulher que pode comer e engordar até a total imobilidade. Assim, o pornô com mulheres gordas zomba da equívoca relação entre sexo e penetração, magreza e sensualidade e do imperativo da intimidade e da privacidade no que se refere ao uso dos prazeres, uma vez que são inúmeros e, muitas vezes, públicos os espaços destinados à alimentação (KULICK, 2012).

Além dos conceitos desenvolvidos por Eliane Moraes e Susan Sontag durante a década de 1980, outra noção pornô é dada por Bernard Arcand, em seu livro El jaguar y el oso hormiguero: antropología de la pornografía (1993). Assim como Susan Sontag, ele elabora uma noção tripartite do pornô, que se distingue pelos diferentes usos e agentes da nomeação: a primeira definição é empírica, diz respeito a um produto de consumo e é dada pelo conteúdo do pornô, pelo mercado e pelas pessoas que mantêm vínculos de trabalho com ele; a segunda definiç̧ão é dada pelos censores e os guardiões da boa ordem moral, social e cultural e, por fim, o Estado estabelece uma definição, 
cumprindo sua função de "defensor do bem-estar social." Para o antropólogo, a pornografia é um espetáculo visual ousado, por vezes obsceno, que ameaça se tornar uma redundância se não se identificar, em cada situação, o que pode ser pornográfico.

Como fenômeno social e produto de mercado, a pornografia é uma etiqueta coletivamente definida que só se torna válida à medida que a sociedade a categoriza, uma vez que, individualmente, qualquer coisa pode causar excitação, inclusive ver um cigarro. Uma das noções relevantes trazidas por Arcand (1993) é a de que revisitar a história da pornografia leva obrigatoriamente à adoção de uma cosmologia geral que define o sexo e a natureza das relações.

Mas, ainda que este autor não considere a pornografia de maneira essencialista e que se define por si só externamente às interações que envolvem o seu uso, a sua noção de pornografia pouco se refere à investigação histórica, dando a ideia de certa estabilidade dos processos sociais que menciona. Como quando ele afirma a necessidade de uma definição concreta e pontual que seja válida para algo além do que o estado atual da sociedade.

A primeira parte da definição pornográfica de Bernard Arcand parece, no entanto, ter ressonância numa perspectiva de estudos realizados por pesquisadores brasileiros sobre convenções de erotismos e sexualidades que têm como importante referência o mercado do sexo. ${ }^{9}$ Um desses trabalhos é a tese Nas redes do sexo: bastidores $e$ cenários do pornô brasileiro, da antropóloga María Elvira Diaz-Benitez (2009). Neste trabalho, ela objetiva analisar a produção de filmes pornôs na cidade de São Paulo e as redes da pornografia que englobam atrizes, atores, criadores, produtores, diretores, fornecedores, recrutadores e distribuidores, bem como outros tentáculos do mercado do sexo: motéis, ruas, boates, revistas, saunas, clubes e casas noturnas. Para a antropóloga, entre os diferentes agentes que compõem a rede, há a percepção de que seus trabalhos são pornografia em decorrência do sexo explícito exibido nas representações. Por outro lado, esses agentes também elaboram noções sobre o pornô, buscando se afastar do estigma associado ao trabalho que realizam, motivo pelo qual, por vezes, eles também qualificam suas atividades como "erótica" ou "adulta".

Diaz-Benitez (2009) observa ainda que os estudos sobre pornografia no Brasil têm utilizado um viés histórico, com foco nas seguintes temáticas: pornografia e mercado editorial (EL FAR, 2002), pornochanchadas em São Paulo entre as décadas de 1970 e 80 (ABREU, 2002), representações da pornografia bizarra e sua relação com a história das depravações sexuais (LEITE JÚNIOR, 2006), representações e corporalidades masculinas em filmes pornôs nacionais (REGES, 2004), relações entre pedofilia e pornografia infantil e implicações legais e sociais (LANDINI, 2005), as maneiras como a crítica literária e cultural tem estabelecido os limites e diferenças entre erotismo e pornografia (FREIRE, 2000), e o debate feminista em torno da pornografia (GREGORI, 2003; GREGORI, 2004).

\footnotetext{
${ }^{9} \mathrm{O}$ mercado do sexo inclui cabarés, bares, sexo virtual on-line, casas de massagem, agências matrimoniais, hotéis, cinemas e revistas pornográficas, etc. Em suma, espaços onde se possa pagar para ter uma experiência sexual ou sensual (AGUSTÍN, 2005).
} 
Como afirmam Gregori e Diaz-Benitez (2012), as pesquisas sobre convenções de erotismo se constituem dentro e a partir do mercado e têm se consolidado como um novo campo de estudos no qual o mercado tornou-se uma figura paradoxal, onde se localizam as experiências e os esforços de normatização, ressignificação e criação de novas alternativas eróticas, que impactam no âmbito das convenções de sexualidade e gênero.

Tais pesquisas têm como textos seminais: “O Negócio do michê” (1987), de Néstor Perlongher, os trabalhos de Adriana Piscitelli sobre turismo sexual e mercado do sexo, a pesquisa sobre sex shops e mercado contemporâneo de bens eróticos, de Maria Filomena Gregori, e outras pesquisas realizadas pelo Núcleo de Estudos de Gênero Pagu, entre as quais "Consumindo lugares, consumindo nos lugares," de Isadora França, "Entre umas e outras: mulheres (homo)sexualidades e diferença na cidade de São Paulo," de Regina Facchini, “À meia luz: uma etnografia imprópria sobre clubes de sexo em São Paulo,” de Camilo Braz (GREGORI, DIAZ-BENITEZ, 2012).

O livro Prazeres dissidentes (2009), organizado por Maria Elvira Diaz-Benitez e Carlos Fígari, alinha-se a essa perspectiva e explora práticas transgressivas que emergem da análise de obras literárias e fílmicas, de espaços de lazer e de encontro, de segmentos da indústria do sexo e de sites da web em contexto latino-americano. Dos vinte artigos, dois publicizam pesquisas que se debruçam mais especificamente sobre o pornô: "Retratos de uma orgia: a efervescência do sexo no pornô," de Maria Elvira Diaz-Benitez e "A pornografia bizarra em três variações;" de Jorge Leite Júnior. Para este autor, a pornografia é "todo tipo de produção escrita, musical, plástica ou audiovisual que seja voltada para um mercado próprio e que tenha como principal objetivo a obtenção do lucro econômico, através da excitação de seu público consumidor" (LEITE JÚNIOR, 2012, p.101).

Assim, embora seja primordial a dispersão e a ambiguidade em torno da palavra pornográfica - tanto do ponto de vista histórico, quanto mercadológico, conceitual e investigativo -, esta noção, em consonância com os estudos brasileiros, defende que a pornografia não se relaciona necessariamente à exibição explícita de genitálias e atos sexuais ou mesmo à avaliação qualitativa de determinadas produções. Sua delimitação é realizada pelo próprio mercado, que disponibiliza as produções para comercialização. Desse modo, pornográfico é aquilo intitulado como tal pelas pessoas enredadas em sua produção.

Consolidando a perspectiva de investigação pornográfica e mercado, o dossiê "Pornôs", publicado na revista Cadernos Pagu no ano passado, analisa noções e práticas exibidas no pornô mainstream, explicitando que a pornografia é um "terreno fértil para pensar como a transgressão de normas de caráter sexual e de gênero convive mútua e contingencialmente com a obediência e a reiteração delas" (GREGORI; DIAZBENITEZ, 2012, p. 8). Vale ressaltar, neste dossiê, o artigo do pesquisador Osmundo Pinho (2012), que oferece uma mirada crítica sobre a articulação entre raça, sexualidade e gênero na pornografia gay, explorando a negritude, a branquidade e a brasilidade associadas ao desejo homossexual.

Por outro lado, há produções teóricas que constituem dissonâncias quanto à ligação entre pornografia e mercado, apresentando outras possibilidades investigativas. 
Estão entre elas o artigo Debates feministas sobre pornografia heteronormativa: estéticas e ideologias da sexualização (2010), dos psicólogos Pedro Pinto, Maria da Conceição Nogueira e João Manuel de Oliveira, que situam a pornografia numa "fenomenologia mais ampla e reflexiva, cruzando uma abordagem feministaconstrucionista com a Psicologia Social crítica." E o artigo Por um feminismo queer: Beatriz Preciado e a pornografia como pre-textos (2009), que discute o conceito de pós-pornografia definido por Preciado (2008) como as diferentes estratégias de crítica e de intervenção que surgiram das revoluções feministas, homossexuais e queer diante dos três regimes pornográficos (museístico, urbano e cinematográfico), das técnicas sexopolíticas modernas de controle do corpo, produção de prazer e divisão dos espaços públicos e privados.

Por fim, argumentamos que é fundamental considerar uma perspectiva histórica ao tratar das produções pornográficas de modo a rejeitar interpretações invariavelmente homogêneas, unívocas e reducionistas. Tal argumento se baseia ainda na ideia de que a obscenidade, um dos elementos-chave nessas produções, noções e ressonâncias, implica em jogos discursivos que são múltiplos, dispersos e ambíguos e que, apenas contingencialmente, atingem contornos definidos.

\section{REFERÊNCIAS}

ABREU, Nuno Cesar. O Olhar pornô. A apresentação do obsceno no cinema e no vídeo. São Paulo: Mercado das letras, 1996.

Boca de lixo, cinema e classes populares. 2002. Tese (Doutorado em Multimeios), Campinas:

\section{Unicamp.}

ALBERTO, Maria de Fátima Pereira et al. Os agentes sociais da rede de proteção e atendimento no enfrentamento da exploração sexual comercial. Psicologia Reflexão e Crítica, Porto Alegre, v. 25, n. 1, 2012. Disponível em: $<$ http://www.scielo.br/scielo.php?script=sci_arttext\&pid=S0102-

$79722012000100016 \& \operatorname{lng}=$ en\&nrm=iso $>$. Acesso em 21 ago. $201 \overline{3}$.

ARCAND, Bernard. El Jaguar y el oso hormiguero: antropología de la pornografía. Buenos Aires: Editorial Nueva Visión, 1993.

ATTWOOD, Feona. The paradigm shift: pornography research, sexualization and extreme images. Sociology compass. Reino Unido. n. 10, 2011, p.13-22.

CHARLES Sébastien. Da infinidade do discurso à finitude do prazer. In SCLIPPA, Norbert (Dir.). Lire Sade. Paris: L'Harmattan, 2004. p. 146-156. Rev. Filos., v. 19, n. 25, jul./dez. 2007, p. 333-344.

COELHO, Salomé. Por um feminismo queer: Beatriz Preciado e a pornografia como pre-textos. Ex aequo, Vila Franca de Xira, n. 20, 2009. Disponível em

$<$ http://www.scielo.gpeari.mctes.pt/scielo.php?script=sci_arttext\&pid=S0874-

$55602009000200004 \& \operatorname{lng}=$ pt\&nrm=iso $>$. Acesso em 21 ago. 2013.

COURT, John. Pornografia: uma resposta cristã. São Paulo: Sociedade Religiosa Edições Vida Nova, 1992.

DIAZ-BENITEZ, Maria Elvira; FÍGARI, Carlos (orgs). Prazeres dissidentes. Rio de Janeiro: CLAM, Garamond Universitária, 2009.

DIAZ-BENITEZ, Maria Elvira. Nas redes do sexo: bastidores e cenários do pornô brasileiro (tese). Rio de Janeiro: UFRJ/Museu Nacional/PPGAS, 2009.

FOUCAULT, Michel. Ditos e escritos. Estética: literatura e pintura, música e cinema. v. 3. MOTTA, Manoel Barros da (Org.). Tradução de Inês Autran Dourado Barbosa. Rio de Janeiro: Forense Universitária, 2001.

FREIRE, João. Prazeres desprezados: a pornografia, seus consumidores e seus detratores. Lugar comum: estúdios de mídia, cultura e democracia. Rio de Janeiro: NEPCOM/UFRJ, nº 12, 2000, p. 65-86. 
GREGORI, Maria Filomena. Relações de violência e erotismo. Cadernos Pagu, n. 20, Campinas: Núcleo de Estudos de Gênero Pagu/Unicamp, 2003, p. 87-120.

Prazer e perigo: notas sobre feminismo, sex-shops e s/m. In: PISCITELLI, A., GREGORI, M.

F.; CARRARRA, S. (orgs). Sexualidades e saberes: convenções e fronteiras. Rio de Janeiro: Garamond Universitária, 2004, p. 235-256.

Unicamp.

Prazeres perigosos. Erotismo, gênero e limites da sexualidade. 2010. Tese (Livre-Docência),

GREGORI, Maria Filomena; DIAZ-BENITEZ, Maria Elvira. Apresentação. Cadernos Pagu. Campinas, n. 38, Jun 2012. Disponível em $<$ http://www.scielo.br/scielo.php?script=sci_arttext\&pid=S0104-

$83332012000100001 \& \operatorname{lng}=\mathrm{en} \& \mathrm{nrm}=\mathrm{iso}>$. Acesso em 28 nov. 2013.

GUERRA, Valeschka Martins; ANDRADE, Fernando Cezar B. de; DIAS, Mardonio Rique. Atitudes de estudantes universitários frente ao consumo de materiais pornográficos. Estudos em psicologia. (Natal), Natal, v. 9, n. 2, Aug. 2004. Disponível em

$<$ http://www.scielo.br/scielo.php?script=sci_arttext\&pid=S1413-

294X2004000200008\&lng=en\&nrm=iso>. Acesso em 21 ago. 2013.

HOUAISS, Antônio. Dicionário Houaiss da Língua Portuguesa. Rio de Janeiro: Ed. Objetiva, 2001.

HUNT, Lynn. A Invenção da pornografia: obscenidade e as origens da Modernidade. São Paulo: Hedra, 1999.

KULICK, Don. Pornô. Cadernos Pagu. Campinas: Unicamp, n.38, p. 223-240, 2012.

LANDINI, T. Horror, honra e direito: violência sexual contra crianças e adolescentes no século XX. 2005. Tese (Doutorado). São Paulo: USP.

LEITE JR, Jorge. Das maravilhas e prodígios sexuais: a pornografia bizarra como entretenimento. São Paulo: Annablume Editora, 2006.

Labirintos conceituais científicos, nativos e mercadológicos: pornografia com pessoas que transitam entre os gêneros. Cadernos Pagu, Campinas-SP, n.38, 2012, p.99-128. Disponível em: http://dx.doi.org/10.1590/S0104-83332012000100004.

MORAES, E. R.; LAPEIZ, S. M. O que é pornografia? São Paulo: Abril Cultural e Brasiliense, 1985.

MORAES, Eliane Robert. O Efeito obsceno. Cadernos Pagu. Campinas, n. 20, 2003. Disponível em $<$ http://www.scielo.br/scielo.php?script=sci arttext\&pid=S0104-

$83332003000100004 \& \operatorname{lng}=$ pt\&nrm=iso $>$. Acesso em 28 nov. 2013.

MORAES, Eliane Robert. Lições de Sade: ensaios sobre a imaginação libertina. São Paulo: Iluminuras, 2011.

MOREIRA, Vivian Lemes.; ROMÃO, Lucília Maria Sousa. Discursos em Movimento: considerações sobre a pedofilia e pornografia infantil na rede. Psico, Porto Alegre; v. 43, n. 4, p. 463-471, out-dez. 2012.

NOGUEIRA, Fernanda. Por um striptease del arte. La gang y el movimento de arte pornô en Brasil. Disponível em <http://fernandanogueira-escritos.blogspot.com.br/2012/09/por-un-striptease-del-arte-elgang-y-el.html>. Acesso em 10 jun. 2013.

SCHAEFER, Luiziana Souto; ROSSETTO, Silvana; KRISTENSEN, Christian Haag. Perícia psicológica no abuso sexual de crianças e adolescentes. Psicologia Teoria e Pesquisa. Brasília, v. 28, n. 2, Jun 2012. Disponível em $<$ http://www.scielo.br/scielo.php?script=sci_arttext\&pid=S0102-

$37722012000200011 \& \operatorname{lng}=\mathrm{en} \& n r m=$ iso $>$. Acesso em 21 ago. 2013.

SONTAG, Susan. A Imaginação pornográfica. In: A Vontade radical. Rio de Janeiro: Companhia das Letras, 1987.

PAES, João Paulo. Nota biográfica. In: Sonetos luxuriosos. São Paulo: Companhia das Letras, 2011.

PRECIADO, Beatriz. Museo, basura urbana y pornografia. Zehar: revista de Arteleku-ko aldizkaria, n. 64, 2008, p. 38-67.

PINHO, Osmundo. Race Fucker: Representações raciais na pornografia gay. Cadernos Pagu. Campinas, n. 38, Jun 2012. Disponível em $<$ http://www.scielo.br/scielo.php?script=sci_arttext\&pid=S0104$83332012000100006 \&$ lng=en\&nrm=iso $>$. Acesso em 28 nov. 2013.

PINTO, Pedro; NOGUEIRA, Maria da Conceição; OLIVEIRA, João Manuel de. Debates feministas sobre pornografia heteronormativa: estéticas e ideologias da sexualização. Psicologia Reflexão e Crítica, Porto Alegre, v. 23, n. 2, 2010. Disponível em 
$<$ http://www.scielo.br/scielo.php?script=sci_arttext\&pid=S0102-

$79722010000200020 \& \operatorname{lng}=$ en\&nrm=iso $>$. Acesso em on 21 ago 2013.

REGES, Marcelo. Brazilian boys: corporalidades masculinas em filmes pornográficos de temática homoerótica. 2004. Dissertação (Mestrado em Antropologia Social). Santa Catarina: Universidade Federal de Santa Catarina.

RUBIN, Gayle. Pensando sobre sexo: notas para uma teoria radical da política da sexualidade, in: Cadernos Pagu, (21), Campinas: Unicamp, 2003, p. 01-88.

TRIMBACH, Randolph. Fantasia erótica e libertinagem masculina no Iluminismo inglês. In: A Invenção da pornografia: obscenidade e as origens da modernidade. São Paulo, Hedra, 1999.

\section{Recebido em 30/08/2014. Aprovado em 07/11/2014.}

Título: Obscenidad refleja: nociones y resonancias pornograficas

Resumen: Este artículo tiene como objetivo discutir articulaciones teóricas y propuestas conceptuales relativos a investigación de pornografía. El estudio utilizó datos de una búsqueda de texto en la base de datos de tesis y disertaciones de la Coordinación de Perfeccionamiento de Personal de Nivel Superior (CAPES), y la Scientific Electronic Library Online (SciELO) en el periodo de julio a diciembre de 2012, y una revisión estudios sobre la investigación de pornografia en Brasil, que se ha abordado la cuestión con referencia a las convenciones del erotismo y la sexualidad y el comercio sexual. Nosotros sostenemos que es crucial tener en cuenta una perspectiva histórica cuando se trata de producciones pornográficas para rechazar las interpretaciones siempre homogéneas, univocas y reduccionistas. Este argumento se basa en la idea de que incluso la obscenidad, uno de los elementos clave en estas producciones, implica juegos discursivos que son múltiples, dispersa y ambigua y que sólo contingentemente, alcanzan contornos.

Palabras-clave: La pornografia. La obscenidad. La investigación bibliográfica. 